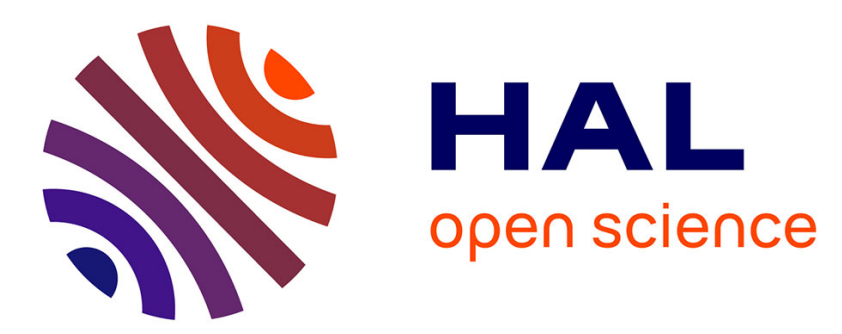

\title{
Characterization of heat sources in the crack tip zone in stretched NR and SBR rubbers
}

\author{
Jose Ricardo Samaca Martinez, Xavier Balandraud, Evelyne Toussaint, \\ Jean-Benoit Le Cam, Daniel Berghezan
}

\section{- To cite this version:}

Jose Ricardo Samaca Martinez, Xavier Balandraud, Evelyne Toussaint, Jean-Benoit Le Cam, Daniel Berghezan. Characterization of heat sources in the crack tip zone in stretched NR and SBR rubbers. European Conference on Constitutive Models for Rubber IX, Sep 2015, Prague, Czech Republic. hal-01136551

\section{HAL Id: hal-01136551 \\ https://hal.science/hal-01136551}

Submitted on 6 May 2020

HAL is a multi-disciplinary open access archive for the deposit and dissemination of scientific research documents, whether they are published or not. The documents may come from teaching and research institutions in France or abroad, or from public or private research centers.
L'archive ouverte pluridisciplinaire HAL, est destinée au dépôt et à la diffusion de documents scientifiques de niveau recherche, publiés ou non, émanant des établissements d'enseignement et de recherche français ou étrangers, des laboratoires publics ou privés. 


\title{
Characterization of heat sources in the crack tip zone in stretched NR and SBR rubbers
}

\author{
J.R. Samaca Martinez \\ Clermont Université, Institut Français de Mécanique Avancée, Université Blaise Pascal, Institut Pascal, \\ CNRS, UMR 6602, Clermont-Ferrand, France \\ Michelin, CERL Ladoux, Clermont-Ferrand, France \\ X. Balandraud \& E. Toussaint \\ Clermont Université, Institut Français de Mécanique Avancée, Université Blaise Pascal, Institut Pascal, \\ CNRS, UMR 6602, Clermont-Ferrand, France
}

J.-B. Le Cam

Université De Rennes 1, Institut de Physique de Rennes, UMR 6251, Campus de Beaulieu, Rennes, France

D. Berghezan

Michelin, CERL Ladoux, Clermont-Ferrand, France

\begin{abstract}
The study deals with the experimental characterization of heat sources produced in a crack tip zone of two types of carbon black filled rubbers: a Styrene Butadiene Rubber (SBR) and a Natural Rubber (NR). For this purpose, full thermal and kinematic field measurements were performed. In NR, crystallisation increases the stiffness in the crack tip zone and consequently decreases the maximum stretch ratio. For SBR specimen, the maximum stretch ratio level at the crack tip is higher than that measured at specimen failure during homogeneous uniaxial tensile tests. During loading, the maximum temperature change is lower in NR specimen than in SBR specimen. For both materials, the heat sources in the crack tip zone remain positive during unloading. This was not observed for homogeneous tests. This phenomenon is due to the very high mechanical dissipation production, and to crystallisation at the beginning of unloading in the case of NR.
\end{abstract}

\section{INTRODUCTION}

Elastomers are materials that exhibit a specific thermal sensitivity related to numerous properties such as entropic elasticity, viscosity, stress softening, as well as strain-induced crystallisation under certain conditions. As regards fracture mechanics in rubbers, the main approach which is developed in the literature is based on the tearing energy (Rivlin \& Thomas 1953). However, the mechanical energy which is involved at the crack tip can be in part mechanically dissipated into heat because of damage, viscous effects and possibly local stress softening, which is not taken into account in the tearing energy. The local measurement of the heat sources produced or absorbed in the crack tip zone can therefore provide information of paramount importance for fracture mechanics in rubber. Such measurements can be performed using full-field measurement techniques (Le Cam 2012, Toussaint et al. 2012).

The aim of the present study was to characterize the thermomechanical response of two types of carbon black filled rubbers in the crack tip zone: Styrene Butadiene Rubber (SBR) and Natural Rubber (NR), this latter being crystallisable under strain. For this purpose, full thermal and kinematic field measurements were performed at constant ambient temperature.

The kinematic analysis focuses on the heterogeneity of the strain states and on the level of maximum stretch ratio reached in the crack tip zone, as well as on possible differences between the loading phase and the unloading phase. The calorimetric analysis focuses on the localization and the intensity of the high heat sources in the crack tip zone, and on total heat produced over a mechanical cycle.

\section{EXPERIMENTAL SETUP}

\subsection{Materials and specimen geometry}

Two types of carbon black filled rubbers were tested: Styrene Butadiene Rubber (SBR) and Natural Rubber (NR), both cured for $22 \mathrm{~min}$ at $150^{\circ} \mathrm{C}$. 
Table 1 summarizes their chemical compositions. It can be seen that, apart from the base material, their formulations were the same. In particular, they were reinforced by the same amount of carbon black fillers. Both materials are subject to viscosity, stress-softening and Mullins effect. Figure 1 shows the preliminary characterization under homogeneous tensile tests (Samaca Martinez et al. 2014a). Note that NR is subject to strain-induced crystallization, leading to an increase in stiffness.

The geometry of the specimens used in the present study is presented in Figure 2. The width, height and thickness were equal to $80 \mathrm{~mm}, 13 \mathrm{~mm}$ and $2 \mathrm{~mm}$, respectively. This corresponds to classic Pure Shear (PS) geometry. The specimens were notched at one of their sides using a razor blade prior to testing. The initial crack length was about $8 \mathrm{~mm}$. This undeformed state geometry was considered as the reference configuration in the present study.

\subsection{Loading conditions}

A load-unload cycle was applied under imposed uniaxial displacement using a $500 \mathrm{~N}$ Instron 5543

Table 1. Chemical composition of the two tested materials, in parts per hundred rubber (phr).

\begin{tabular}{|c|c|c|}
\hline & NR & SBR \\
\hline Natural rubber & 100 & \\
\hline Styrene-butadiene rubber & & 100 \\
\hline Carbon black & 50 & 50 \\
\hline Antioxidant 6PPD & 1.9 & 1.9 \\
\hline Stearic acid & 2 & 2 \\
\hline Zinc oxide $\mathrm{ZnO}$ & 2.5 & 2.5 \\
\hline Accelerator CBS & 1.6 & 1.6 \\
\hline Sulfur solution $2 \mathrm{H}$ & 1.6 & 1.6 \\
\hline
\end{tabular}

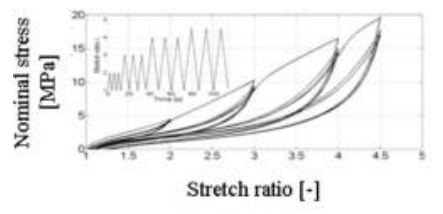

SBR

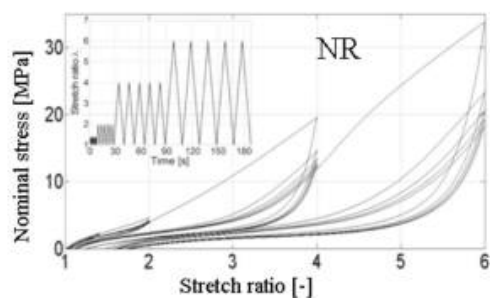

Figure 1. Preliminary characterization under homogeneous tensile tests on NR and SBR specimens.

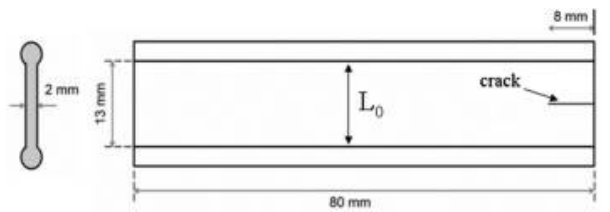

Figure 2. Specimen geometry.
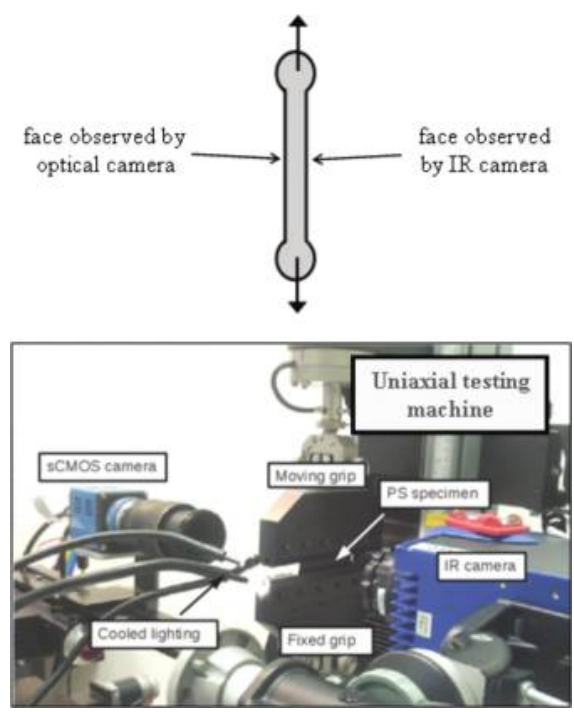

Figure 3. Experimental setup.

testing machine (see Fig. 3). The signal shape was triangular in order to ensure a global constant strain rate during loading and unloading. The maximum global stretch ratio $\lambda_{g}=L / L_{0}$ was equal to 1.5 . The global strain rate was equal to $\pm 0.26 \mathrm{~s}^{-1}$.

\subsection{Displacement and temperature measurements}

The kinematic fields were measured using the Digital Image Correlation (DIC) technique, which consists of correlating the grey levels between two different images of an observed region of the specimen surface named "Region of Interest" (ROI) (Sutton et al. 1983). Images were recorded using a cooled 16-bit PCO-Edge sCMOS camera. The sensor of the camera features $2650 \times 2160$ pixels. The acquisition frequency $f_{a}$ was set to $50 \mathrm{~Hz}$. The software employed for the correlation process was SeptD (Vacher et al. 1999). A set of sub-images was considered to determine the displacement field of a given image with respect to a reference image. Each sub-image is referred to as a "Zone of Interest" (ZOI). A bilinear correlation function was employed to calculate the displacement of the centre of a given ZOI between the two images. 
Correlation parameters were chosen to reach a spatial resolution of 10 pixels, corresponding to $101 \mu \mathrm{m}$. Temperature measurements were carried out using a Cedip Jade III-MWIR infrared (IR) camera, featuring $320 \times 240$ pixels and detectors with a wave length range of $3.5-5 \mu \mathrm{m}$. The same acquisition frequency $f_{a}$ as for the kinematic measurements was chosen: $50 \mathrm{~Hz}$. In fact, each recorded image is the average of two successive images captured at $100 \mathrm{~Hz}$ to improve the resolution of the measurement. The calibration of the camera detectors was performed using a black body and employing a two-point Non-Uniformity Correction (NUC) procedure. The spatial resolution of the temperature fields is the size of the pixel on the surface of the specimen. It was here equal to $62.5 \mu \mathrm{m}$.

\subsection{Heat source reconstruction}

The thermal quantity used to calculate heat sources is actually the temperature change with respect to the initial temperature map in the reference configuration. Since the specimen undergoes large deformations and as the thermal fields are captured in the deformed configuration, the correspondence between the current geometry and the reference geometry must be implemented: see Figure 4. A motion compensation technique was developed to follow the temperature change at any material point (Toussaint et al. 2012). The output is used further to construct the heat source fields in the reference configuration, using the heat diffusion equation. The three-dimensional version of this equation can be written (Chrysochoos \& Louche 2000, Samaca Martinez et al. 2014b, Samaca Martinez et al. 2015)

$\rho_{0} C_{E, V k} \frac{\partial T}{\partial t}-\operatorname{Div}\left(\mathrm{K}_{0} \operatorname{Grad} T\right)-R=S$

where:

- $S$ and $R$ are the total heat source produced or absorbed by the material due to stretch and the external heat source by radiation, respectively. $S$ is composed of two parts: thermo-mechanical couplings and mechanical dissipation (also named intrinsic dissipation);

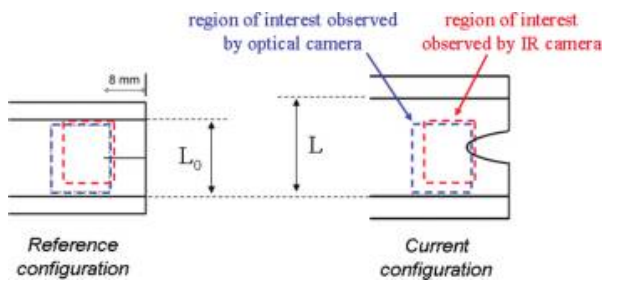

Figure 4. Regions of interest.
- $\rho_{0}$ is the density of the material, $\mathrm{K}_{0}$ the thermal conductivity tensor and $C_{E, V k}$ the specific heat at constant strain $\mathrm{E}$ and $\mathrm{V}_{\mathrm{k}}\left(\mathrm{V}_{\mathrm{k}}\right.$ are the other state variables characterizing the state of the material apart from temperature and strain).

In the case of a thin specimen in the plane $(\mathrm{X}, \mathrm{Y})$, Equation 1 can be reduced to the following two-dimensional formulation from several hypothesis (Samaca Martinez et al. 2014b, Samaca Martinez et al. 2015):

$$
\rho_{0} C_{E, V k}\left(\frac{\partial \theta}{\partial t}+\frac{\theta}{\tau_{2 D}}\right)-k_{0} \Delta_{2 D} \theta=S
$$

where

- $\theta(X, Y, t)$ is the field of temperature change with respect to the initial temperature map;

- $\Delta_{2 \mathrm{D}}$ is the Laplacian operator in the specimen plane in the $(X, Y)$ Lagrangian coordinate system;

- $k_{0}$ is the thermal conductivity coefficient of the material assumed to be isotropic;

- $\tau_{2 \mathrm{D}}$ is a time constant which characterizes the heat exchanges by convection with the air at the specimen surface.

By dividing Equation 2 by $\rho_{0} \mathrm{C}_{\mathrm{E}, \mathrm{Vk}}$, it comes

$$
\frac{\partial \theta}{\partial t}+\frac{\theta}{\tau_{2 D}}-D_{0} \Delta_{2 D} \theta=\frac{S}{\rho_{0} C_{E, V k}}
$$

where $D_{0}$ is the thermal diffusivity coefficient of the material. The heat source $S$ is expressed in $\mathrm{W} / \mathrm{m}^{3}$. However this quantity can be expressed in ${ }^{\circ} \mathrm{C} / \mathrm{s}$ by dividing it by $\rho_{0} C_{\mathrm{E}, \mathrm{Vk}}$. This unit enables us to directly read the temperature rate that would be observed in the case of adiabatic variation.

\section{RESULTS}

\subsection{Kinematical results}

Figure 5 presents the map of local strain states obtained from the kinematical measurements for both materials (Samaca Martinez et al. 2014b, Samaca Martinez et al. 2015). We observe that the mechanical strain state at any material point of the gauge zone ranges between PS (pure shear) and UT (uniaxial tension). As expected, the zone which is far from the crack tip is in PS in the (X,Y) plane. The representation adopted in this figure enables us to define the zone of influence of the crack. It corresponds to the zone which is not in PS. It extends about $8 \mathrm{~mm}$ from the crack tip. The zones above and below the crack lips are in UT. At the crack tip, the strain state is close to PS in plane $(\mathrm{X}, \mathrm{Z})$. 


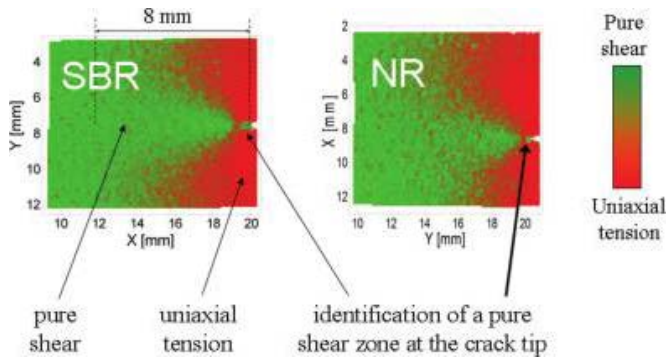

Figure 5. Maps of local strain states obtained from the kinematical measurements.

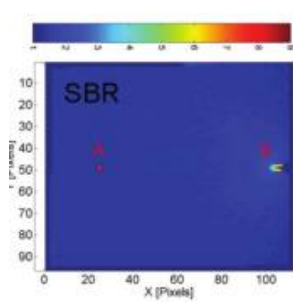

a)

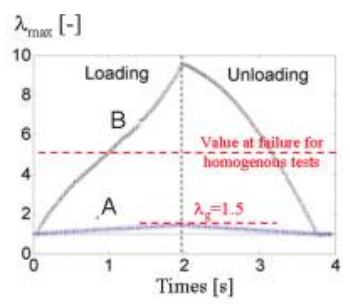

b)
Figure 6. Kinematic results obtained for the SBR specimen: a) map of maximum stretch ratio $\lambda_{\max }$ for the maximum load, b) evolution of $\lambda_{\max }$ at two points $\mathrm{A}$ and $\mathrm{B}$.

Figure 6a presents the map of the maximum stretch ratio $\lambda_{\max }$ for the maximum load. $\lambda_{\max }$ is quite homogeneous over all the specimen surface except in the vicinity of the crack tip zone. Figure $6 \mathrm{~b}$ presents the variation in the maximum stretch ratio at two different points. Point $\mathrm{A}$ is located out of the zone of influence of the crack and point $\mathrm{B}$ is located in the crack tip zone, where its value is the highest. Three comments can be made from this figure:

- at point A, the variation corresponds to the global stretch ratio variation;

- at point B, the maximum stretch ratio for the maximum load is equal to 9.5. It must be noted that even if this value depends on the data processing (chosen correlation parameters), it is much higher than the stretch ratio at failure in a homogeneous PS test (approximately 5). In the latter case, failure occurs from the lowest mechanical strength zone. This high stretch ratio value corresponds to the limit of chain extensibility. Indeed, by fitting the stress-strain curves obtained with constitutive models to reflect limiting chain extensibility (Gent 1996), the maximum chain extensibility corresponds to a stretch ratio of about 10 ;

- at point B, the curve shape between loading and unloading is not symmetrical.
It can be seen from Figure 7 that $\lambda_{\max }$ is lower in the NR specimen than in the SBR specimen: 5.1 compared to 9.5 for the maximum load. This can be explained by crystallization in the NR specimen, which increases the stiffness in the crack tip zone. Thus, in terms of heat production, crystallization acts in two opposite ways in the crack tip zone. On the one hand, crystallization locally produces additional heat. On the other hand, the increase in stiffness resulting from crystallization reduces the local level of stretching, thus reducing the quantity of heat produced by the material.

\subsection{Calorimetric results}

Figure 8 presents the comparison between the maps of temperature change $\theta$ of the two specimens near the crack tip, for the maximum load. It can be seen that the 'hot' zone is larger in the NR specimen than in the SBR specimen. This can be explained by the fact that crystallization occurs in a large zone around the crack tip in NR (Trabelsi et al. 2002).

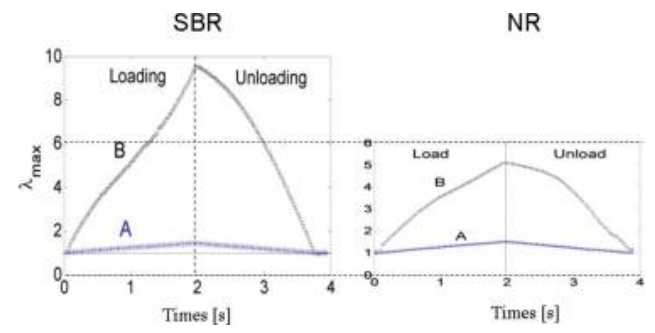

Figure 7. Comparison between NR and SBR in terms of evolution of $\lambda_{\max }$ at the two points $\mathrm{A}$ and $\mathrm{B}$.

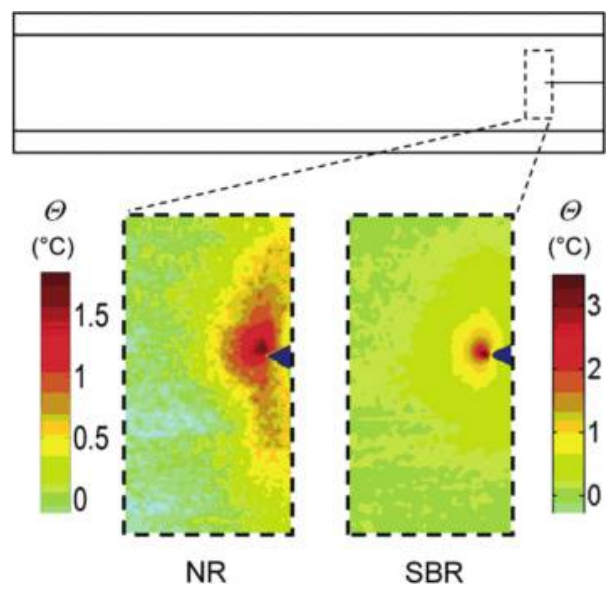

Figure 8. Comparison between NR and SBR specimens in terms of map of temperature change $\theta$ near the crack tip for the maximum load. 


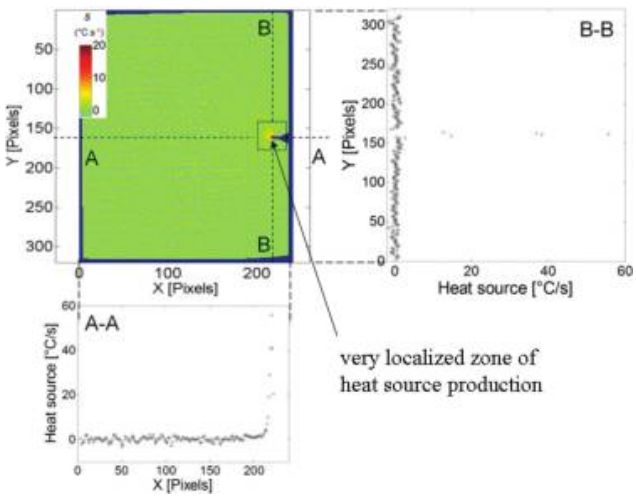

Figure 9. Heat source map in the SBR specimen for the maximum load. The maximum value of the heat source is equal to $56^{\circ} \mathrm{C} / \mathrm{s}$ but the colour scale is limited to $20^{\circ} \mathrm{C} / \mathrm{s}$ for a better visualization of the heat source localization.

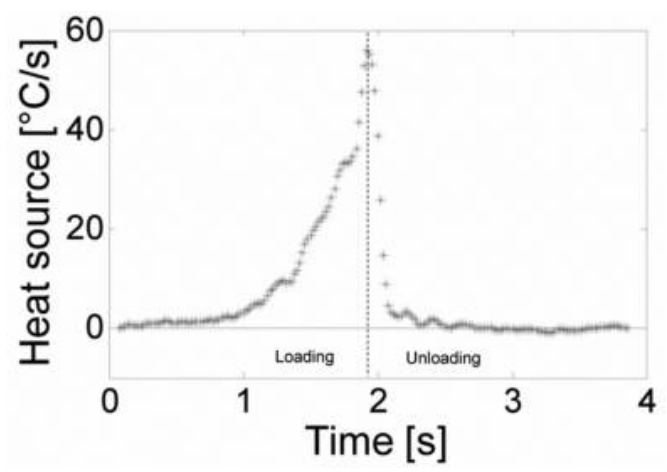

Figure 10. Heat source versus time at the crack tip for SBR.

Figure 9 shows the heat source map in the SBR specimen for the maximum load. Two profiles enable us to observe the heat source concentration near the crack tip. A strong localization is observed very close to the crack tip. The heat source localization corresponds to a zone of about 7 pixels (horizontal profile $\mathrm{A}-\mathrm{A}$ ) by 5 pixels (vertical profile B-B), corresponding to about $0.44 \times 0.32 \mathrm{~mm}^{2}$. Outside this zone, the heat sources are negligible compared to the maximum heat source, which is equal to $56^{\circ} \mathrm{C} / \mathrm{s}$.

Figure 10 presents the variation in time of the heat source in the crack tip vicinity at point B (see Fig. 6), where the heat source value is the highest. Some comments can be made for the loading phase:

- the heat source first slightly and quasi-linearly increases. This is in agreement with heat sources due to entropic coupling (Samaca Martinez et al. 2013a, Le Cam et al. 2013), with possible additional small mechanical dissipation;

- the heat source then strongly increases. It can be split into two contributions: that of the entropic coupling and that of the mechanical dissipation, if any. The former quantity is positive for a positive strain rate. The latter is always positive as it is related to mechanical irreversibilities, such as damage or viscosity.

Figure 10 also shows that the heat source remains positive during the unloading phase: first it strongly decreases, then progressively returns to zero. The entropic coupling heat source is expected to be negative since the strain rate is negative. This means that, during unloading, there is the production of a (positive) mechanical dissipation whose amplitude is higher than the entropic coupling term. This result shows that the crack tip is a zone which always produces heat during cyclic tests, favouring the self-heating of this zone. Consequently, this zone is probably more affected by phenomena such as thermo-oxidation. To the best of the authors' knowledge, this result has never been reported in the literature.

Figure 11a shows the heat source map for the maximum load in the NR specimen, for comparison purposes with the SBR specimen. The zone of the highest values corresponds to the vicinity of the crack tip. The fact that the maximum value (equal to about $8^{\circ} \mathrm{C} / \mathrm{s}$ ) is not exactly located at the crack tip but slightly shifted upwards is not interpretable due to the fact that the spatial resolution is greater than the distance between the point at which the heat source is maximum and the crack tip (Samaca Martinez et al. 2014b). The zone of high heat source around the crack tip is less localized that in SBR specimen. It can be noted that its size is close to the size of the crystallized zone observed by Trabelsi et al. (2002). Its size and shape are also close to those of the crystallized zone observed by Rublon et al. (2013).

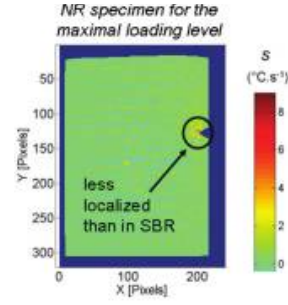

a)

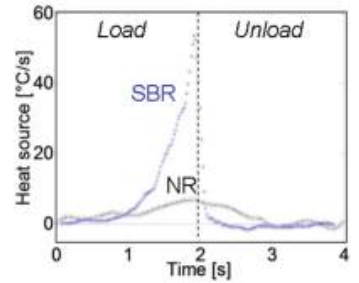

b)
Figure 11. a) Heat source map in the NR specimen for the maximum load, b) Comparison between NR and SBR in terms of evolution the heat source in the crack tip zone. 
Figure 11b shows that the heat source level at the crack tip is lower in the NR specimen than in the SBR specimen. For both specimens, the heat sources remain positive and high at the beginning of unloading. It can be noted that in the NR specimen, this phenomenon lasts longer. This can be explained by the continuation of the crystallization process. Even though the maximum stretch ratios are different in NR and SBR, the heat sources at the crack tip remain positive at the beginning of unloading.

\section{CONCLUSION}

Infrared thermography and digital image correlation have been used simultaneously to analyse the thermomechanical behaviour at the crack tip of a filled crystallisable rubber (NR) and a filled noncrystallisable rubber (SBR). Both specimens were subjected to the same load-unload mechanical cycle. Several results were obtained:

- the calorimetric results showed that the heat produced in the crack tip zone is lower for the NR specimen than for SBR;

- the 'hot' zone is larger in NR50, due to straininduced crystallization;

- even though strain-induced crystallization produces additional heat, crystallites act as fillers and increase stiffness in the crack tip zone, which leads to a decrease in the stretch level in this zone. In other words, crystallization acts in two opposite ways in terms of heat production. This is an important consideration for the study of the self-heating of cracked rubbers subjected to fatigue loadings;

- it was observed that, similarly to noncrystallisable SBR, the heat sources in the crack tip zone in NR remain positive during unloading. This was not observed for homogeneous tests: see (Samaca Martinez et al. 2013b) and (Samaca Martinez et al. 2014a). This phenomenon is due to the production of mechanical dissipation (and to a continuation of crystallization at the beginning of unloading in the case of NR) that is of the same order of magnitude as the heat source absorbed due to entropic coupling.

This study is the first one characterizing experimentally the heat source fields at the crack tip of elastomeric rubbers.

\section{ACKNOWLEDGEMENTS}

The authors would like to acknowledge the "Manufacture Française des Pneumatiques Michelin" for supporting this study. The authors also thank J. Caillard for the fruitful discussions.

\section{REFERENCES}

Chrysochoos, A. \& Louche, H. 2000. An infrared image processing to analyse the calorific effects accompanying strain localisation. Int J Eng Sci 38: 1759-1788.

Gent, A.N. 1996. A new constitutive relation for rubber. Rubber Chem Technol, 69: 59-61.

Le Cam, J.-B. 2012. A review of the challenges and limitations of full-field measurements applied to large heterogeneous deformations of rubbers. Strain 48: 174-188.

Le Cam, J.-B., Samaca Martinez, J.R., Balandraud, X., Toussaint, E. \& Caillard, J. 2013. Thermomechanical analysis of the singular behavior of rubber: entropic elasticity, reinforcement by fillers, strain-induced crystallization and the Mullins effect. Exp Mech 55: 771-782.

Rivlin, R.S. \& Thomas, A.G. 1953. Rupture of rubber. I. Characteristic energy for tearing. J Polym Sci 10: 291-318.

Rublon, P., Huneau, B., Saintier, N., Beurrot, S., Leygue, A., Verron, E., Mocuta, C., Thiaudière, D. \& Berghezan, D. 2013. In situ synchrotron wide-angle $\mathrm{X}$-ray diffraction investigation of fatigue cracks in natural rubber. J Synchrotron Radiat 20: 105-109.

Samaca Martinez, J.R., Le Cam, J.-B., Balandraud, X., Toussaint, E. \& Caillard, J. 2013a. Mechanisms of deformation in crystallizable natural rubber. Part 2: Quantitative calorimetric analysis. Polymer 54: 2727-2736.

Samaca Martinez, J.R., Le Cam, J.-B., Balandraud, X., Toussaint, E. \& Caillard, J. 2013b. Filler effects on the thermomechanical response of stretched rubbers. Polym Test 32: 835-841.

Samaca Martinez, J.R., Le Cam, J.B., Balandraud, X., Toussaint, E. \& Caillard, J. 2014a. New elements concerning the Mullins effect: a thermomechanical analysis. Eur Polym J 55: 98-107.

Samaca Martinez, J.R., Balandraud, X., Toussaint, E., Le Cam, J.-B. \& Berghezan, D. 2014b. Thermomechanical analysis of the crack tip zone in stretched crystallizable natural rubber by using infrared thermography and digital image correlation. Polymer 55: 6345-6353.

Samaca Martinez, J.R., Toussaint, E., Balandraud, X., Le Cam, J.-B. \& Berghezan, D. 2015. Heat and strain measurements at the crack tip of filled rubber under cyclic loadings using full-field techniques. Mech Mater 81: 62-71.

Sutton, M.A., Wolters, W.J., Peters, W.H., Ranson, W.F. \& McNeill, S.R. 1983. Determination of displacements using an improved digital correlation method. Image Vision Comput 1: 133-139.

Toussaint, E., Balandraud, X., Le Cam, J.-B. \& Grédiac, M. 2012. Combining displacement, strain, temperature and heat source fields to investigate the thermomechanical response of an elastomeric specimen subjected to large deformations. Polym Test 31: 916-925.

Trabelsi, S., Albouy, P.A. \& Rault, J. 2002. Stress-induced crystallization around a crack tip in natural rubber. Macromolecules 35: 10054-10061.

Vacher, P., Dumoulin, S., Morestin, F. \& Mguil-Touchal, S. 1999. Bidimensional strain measurement using digital images. Proc Inst Mech Eng Part C 213: 811-817. 